\title{
Effect of repeated immersion solution cycles on the color stability of denture tooth acrylic resins
}

\author{
Paulo Maurício Batista da SILVA¹, Emílio José Tabaré Rodríguez ACOSTA², Matheus JACOBINA², Luciana de Rezende \\ PINTO $^{3}$, Vinícius Carvalho PORTO ${ }^{4}$
}

1- DDS, MSc, PhD student, Department of Prosthodontics, Bauru School of Dentistry, University of São Paulo, Bauru, SP, Brazil.
2- DDS, MSc, Department of Prosthodontics, Bauru School of Dentistry, University of São Paulo, Bauru, SP, Brazil.
3- DDS, MSc, PhD, Department of Prosthodontics, Bauru School of Dentistry, University of São Paulo, Bauru, SP, Brazil.
4- DDS, MSc, PhD, Associate Professor, Department of Prosthodontics, Bauru School of Dentistry, University of São Paulo, Bauru, SP, Brazil.

Corresponding address: Prof. Dr. Vinícius Carvalho Porto - Faculdade de Odontologia de Bauru - USP - Departamento de Prótese - Al. Dr. Octávio Pinheiro Brisolla, n 9-75 - Bauru - São Paulo - Brasil - 17012-901 - Phone: +55 (14) 3235-8277 - e-mail vcporto@fob.usp.br

Received: October 20, 2009 - Modification: July 04, 2011 - Accepted: July 14, 2011

\section{ABSTRACT}

$\mathrm{O}$ bjective: Chemical solutions have been widely used for disinfection of dentures, but their effect on color stability of denture tooth acrylic resins after repeated procedures is still unclear. The aim of this in vitro study was to evaluate whether repeated cycles of chemical disinfectants affected the color stability of two denture tooth acrylic resins. Material and Methods: Sixty disc-shaped specimens ( $40 \mathrm{~mm} \times 3 \mathrm{~mm}$ ) were fabricated from two different brands (Artiplus and Trilux) of denture tooth acrylic resin. The specimens from each brand $(n=30)$ were randomly divided into 6 groups $(n=5)$ and immersed in the following solutions: distilled water (control group) and 5 disinfecting solutions (1\% sodium hypochlorite, $2 \%$ sodium hypochlorite, $5.25 \%$ sodium hypochlorite, $2 \%$ glutaraldehyde, and $4 \%$ chlorhexidine gluconate). Tooth color measurements were made by spectrophotometry. Before disinfection, the initial color of each tooth was recorded. Further color measurements were determined after subjecting the specimens to $7,21,30,45,60$, and 90 immersion cycles in each tested solution. Color differences $\left(\Delta \mathrm{E}^{*}\right)$ were determined using the CIE L*a*b* color system. Data were analyzed using two-way repeated measures analysis of variance (ANOVA) followed by Tukey tests. The significance level was set at $5 \%$. Results: There were statistically significant differences in $\Delta \mathrm{E}^{*}$ among the 5 disinfectants and water during the 90 cycles of immersion for both denture tooth acrylic resins. Distilled water promoted the greatest color change in both denture tooth acrylic resins, nevertheless none of tested disinfectants promoted $\Delta \mathrm{E}^{*}$ values higher than 1.0 on these acrylic materials during the 90 cycles of disinfection. Conclusions: Repeated immersion cycles in disinfecting solutions alter $\Delta \mathrm{E}^{*}$ values, however these values do not compromise the color of the tested denture tooth acrylic resins because they are imperceptible to the human eye.

Key words: Disinfectants. Polymethyl methacrylate. Color perception tests.

\section{INTRODUCTION}

Complete dentures are daily exposed to normal oral microbial flora, which include bacteria, viruses and fungi ${ }^{22}$. Furthermore, oral and nonoral pathogenic organisms associated with local and systemic diseases have been cultured from contaminated dentures ${ }^{19,20}$. Therefore these dentures may function as a reservoir of infection ${ }^{4}$, since their surface irregularities facilitate the colonization and penetration of these microorganisms into the resin ${ }^{18}$.
Denture hygiene has been recommended for denture decontamination and for maintaining their serviceability ${ }^{11}$. Denture cleansers have been studied to identify the ideal product to eliminate microorganisms ${ }^{21}$. Efficient chemical solutions may be an alternative, especially for geriatric or handicapped denture wearers whose manual dexterity may be compromised?

When choosing a disinfectant solution for dentures, its compatibility with the type of material to be disinfected should be considered to avoid adverse effects ${ }^{15}$. Ideally, the physical and 
mechanical properties of denture base and artificial denture tooth resins should remain unaltered after the disinfection process. Nevertheless, it has been demonstrated that the hardness ${ }^{14}$, flexural strength $^{13}$ and color stability ${ }^{11}$ of denture base resins can be notably affected by disinfectants such as glutaraldehyde, chlorhexidine and hypochlorite.

In this scenario, color stability of dentures is an important factor in treatment acceptance by the patient. It is very important for esthetic restorative materials that the color of the materials remains stable over a long period in the oral environment. The color change may be visibly noticed or may be more precisely assessed by spectrophotometry ${ }^{10,17}$.

The effect of disinfecting solutions on the color stability of denture tooth acrylic resins has not yet been reported ${ }^{15}$. Thus, the aim of this in vitro study was to analyze by spectrophotometry the color stability of these materials when exposed to successive immersion solution cycles.

\section{MATERIAL AND METHODS}

\section{Preparation of specimens}

Two brands of denture tooth acrylic resin were selected for this study: Artiplus (Dentsply International, Inc., York, PA, USA) and Trilux (Dental VIPI Ltda, Pirassununga, SP, Brazil) (Figure 1). Upon request, the manufacturers provided specimens of their materials shaped into discs $(40 \mathrm{~mm} \times 3$ $\mathrm{mm}$ ) and fabricated in accordance with the same directions used to process the denture teeth. For each denture tooth acrylic resin, 30 specimens were prepared, totalizing 60 samples.

\section{Chemical solutions}

Specimens were randomly divided into 6 groups consisting of 5 specimens of each denture tooth acrylic resin 6,11 , according to the tested solution (Figure 2), and they were numbered in order to allow comparison between each evaluation period. The same volume of all solutions was used and prepared by the same pharmacy (Calêndula Farma Farmácia de Manipulacão Ltda, Bauru, SP, Brazil). The application time of each solution tested was based on results from other studies and recommendations of their respective manufacturers, which show that these times are necessary to ensure high antimicrobial efficacy of these products.

\section{Color measurements}

Color measurements of each specimen were taken before immersion and after 7, 21, 30, 45, 60, and 90 immersion cycles for each tested solution. Before each disinfection procedure, the specimens were rinsed with distilled water for 3 min and dried with tissue paper to ensure the achievement of rapid readings by spectrophotometry without dehydration of the resin material. After this, the samples were immediately immersed in their respective solutions. All chemical solutions were renewed after each disinfection procedure.

Color measurements were evaluated using a Spectro-guide spectrophotometer (BYK-Gardner GmbH, Geretsried, Germany). Before each measurement session, the spectrophotometer was calibrated with its white reference tile, using the white calibration standard provided, according the manufacturer's instructions. In order to standardize sample's color measurement, a positioning jig was used to position the measuring port of the instrument to the same location on the specimen for repeated measures ${ }^{11}$. The spectrophotometer was set to multimeasure mode in which three readings were taken in the center of the samples (right side, middle and left side) and then more three similar readings were performed perpendicularly to the previous one. Then, the mean value of these readings was recorded. This number of readings was established in the study to ensure broader readings of the samples, since the of spectrophotometer's active tip diameter is smaller than the specimens' diameter. The lighting conditions of the area in which measurements were taken were constant throughout the data collection period.

The color change values of all specimens were calculated by mean and standard deviation of $\Delta \mathrm{E}^{*}$ with the use of CIE L*a*b* color system. Individual analysis was performed using the three variables inherent to the device, in which $L^{*}$ represents the coordinate the lightness or darkness of the object, a* indicates the red-green chromaticity of the

Figure 1- Denture tooth acrylic resins used in this study

\begin{tabular}{|c|c|c|c|}
\hline Product & Code & Manufacturer & Composition \\
\hline Artiplus & $\mathrm{A}$ & $\begin{array}{c}\text { Dentsply } \\
\text { International }\end{array}$ & IPN-PMMA \\
\hline Trilux & $\mathrm{T}$ & Dental VIPI - Brazil & IPN-PMMA \\
\hline
\end{tabular}

*PMMA: Poly(methylmethacrylate); IPN: Interpenetrating PolymerNetwork.

Figure 2- Chemical solutions tested in this study

\begin{tabular}{|l|c|c|}
\hline \multicolumn{1}{|c|}{ Solution } & Code & $\begin{array}{c}\text { Immersion } \\
\text { time (min) }\end{array}$ \\
\hline Distilled water & $\mathrm{W}$ & 10 \\
\hline $1 \%$ Sodium hypochlorite & $\mathrm{H} 1 \%$ & 10 \\
\hline $2 \%$ Sodium hypochlorite & $\mathrm{H} 2 \%$ & 5 \\
\hline $5.25 \%$ Sodium hypochlorite & $\mathrm{H} 5.25 \%$ & 5 \\
\hline $2 \%$ Glutaraldehyde & $\mathrm{G} 2 \%$ & 10 \\
\hline $4 \%$ Chlorhexidine gluconate & $\mathrm{GC} 4 \%$ & 10 \\
\hline
\end{tabular}


Table 1- $\Delta \mathrm{E}^{*}$ mean and standard deviation (SD) for each denture tooth resin material according to the tested solutions within each period of immersion

\begin{tabular}{|c|c|c|c|c|c|c|c|}
\hline \multirow[t]{2}{*}{ Material } & \multirow[t]{2}{*}{ Solution } & \multicolumn{6}{|c|}{$\Delta \mathrm{E}^{*}$ mean and $\mathrm{SD}$} \\
\hline & & 7th cycle & 21st cycle & 30th cycle & 45th cycle & 60th cycle & 90th cycle \\
\hline & W & $0.268 \pm 0.038^{\mathrm{Aa}}$ & $0.862 \pm 0.072^{\mathrm{Ab}}$ & $0.870 \pm 0.118^{\mathrm{BCb}}$ & $0.880 \pm 0.132^{\mathrm{Ab}}$ & $0.844 \pm 0.125^{\mathrm{Ab}}$ & $0.798 \pm 0.119^{\mathrm{Bb}}$ \\
\hline & $\mathrm{H} 1 \%$ & $0.266 \pm 0.095^{\mathrm{Aa}}$ & $0.888 \pm 0.136^{A b}$ & $0.696 \pm 0.060^{A C}$ & $0.738 \pm 0.060^{A b c}$ & $0.688 \pm 0.066^{\text {Acd }}$ & $0.534 \pm 0.050^{\mathrm{Ad}}$ \\
\hline \multirow[t]{6}{*}{ A } & $\mathrm{H} 2 \%$ & $0.238 \pm 0.065^{\mathrm{Aa}}$ & $0.820 \pm 0.044^{\mathrm{Ab}}$ & $0.764 \pm 0.105^{\text {ACbd }}$ & $0.728 \pm 0.041^{\mathrm{Ab}}$ & $0.836 \pm 0.058^{\mathrm{Abd}}$ & $0.664 \pm 0.129^{A B C d}$ \\
\hline & H5.25\% & $0.228 \pm 0.039^{\mathrm{Aa}}$ & $0.900 \pm 0.075^{\mathrm{Ab}}$ & $0.806 \pm 0.054^{\mathrm{ACC}}$ & $0.830 \pm 0.064^{\mathrm{Ac}}$ & $0.816 \pm 0.048^{\mathrm{AC}}$ & $0.718 \pm 0.058^{\mathrm{BCd}}$ \\
\hline & $\mathrm{G} 2 \%$ & $0.204 \pm 0.047^{\mathrm{Aa}}$ & $0.806 \pm 0.019^{A b}$ & $0.714 \pm 0.026^{A c}$ & $0.790 \pm 0.035^{\mathrm{Ab}}$ & $0.780 \pm 0.071^{\mathrm{Abc}}$ & $0.588 \pm 0.021^{\mathrm{Ad}}$ \\
\hline & GC4\% & $0.192 \pm 0.013^{\mathrm{Aa}}$ & $0.906 \pm 0.072^{\mathrm{Ab}}$ & $0.710 \pm 0.060^{\mathrm{Ac}}$ & $0.874 \pm 0.092^{\mathrm{Ab}}$ & $0.726 \pm 0.100^{\mathrm{Ac}}$ & $0.542 \pm 0.055^{\mathrm{Ad}}$ \\
\hline & W & $0.358 \pm 0.023^{\mathrm{Aa}}$ & $0.698 \pm 0.021^{A b c}$ & $0.676 \pm 0.166^{\mathrm{Bb}}$ & $0.902 \pm 0.207^{\mathrm{Bc}}$ & $0.702 \pm 0.043^{\mathrm{Abc}}$ & $0.628 \pm 0.063^{\mathrm{Ab}}$ \\
\hline & $\mathrm{H} 1 \%$ & $0.616 \pm 0.069^{\mathrm{Bab}}$ & $0.978 \pm 0.556^{\mathrm{Ba}}$ & $0.474 \pm 0.136^{\mathrm{Ab}}$ & $0.550 \pm 0.218^{\mathrm{Ab}}$ & $0.450 \pm 0.048^{\mathrm{Bb}}$ & $0.326 \pm 0.111^{\mathrm{cb}}$ \\
\hline \multirow[t]{4}{*}{$\mathrm{T}$} & $\mathrm{H} 2 \%$ & $0.344 \pm 0.036^{\mathrm{Aa}}$ & $0.686 \pm 0.028^{A b c}$ & $0.662 \pm 0.053^{\mathrm{Bbc}}$ & $0.720 \pm 0.032^{A B C}$ & $0.632 \pm 0.014^{\mathrm{Ab}}$ & $0.640 \pm 0.030 \mathrm{~A}^{\mathrm{b}}$ \\
\hline & $\mathrm{H} 5.25 \%$ & $0.346 \pm 0.019^{\mathrm{Aa}}$ & $0.704 \pm 0.046^{\mathrm{Ab}}$ & $0.662 \pm 0.033^{\mathrm{ABD}}$ & $0.700 \pm 0.044^{\mathrm{ABb}}$ & $0.686 \pm 0.029^{A b}$ & $0.552 \pm 0.086^{\mathrm{ABb}}$ \\
\hline & $\mathrm{G} 2 \%$ & $0.324 \pm 0.041^{\mathrm{Aa}}$ & $0.692 \pm 0.066^{\mathrm{Ab}}$ & $0.648 \pm 0.044^{\mathrm{ABbc}}$ & $0.746 \pm 0.033^{\mathrm{ABb}}$ & $0.684 \pm 0.047^{\mathrm{Ab}}$ & $0.554 \pm 0.058^{\mathrm{ABC}}$ \\
\hline & GC4\% & $0.324 \pm 0.038^{\mathrm{Aa}}$ & $0.658 \pm 0.035^{A b}$ & $0.600 \pm 0.092^{\mathrm{ABbc}}$ & $0.678 \pm 0.060^{\mathrm{ABb}}$ & $0.646 \pm 0.090^{\mathrm{Ab}}$ & $0.502 \pm 0.038^{\mathrm{ABC}}$ \\
\hline
\end{tabular}

$\Delta \mathrm{E}^{*}$ means followed by the same letters are not significantly different. Uppercase letters for vertical comparisons and lowercase letters for horizontal comparisons. A: Artiplus; T: Trilux.

object, and b* corresponds to the yellow/blue axis of the object.

Color differences $\left(\Delta \mathrm{E}^{*}\right)$ of specimens were calculated using the formula: $\Delta \mathrm{E}^{*}=\left\{\left(\Delta \mathrm{L}^{*}\right)^{2}+(\Delta \mathrm{a} *)^{2}+\left(\Delta \mathrm{b}^{*}\right)^{2}\right\}^{1 / 2}{ }^{10}$, where $\Delta \mathrm{L}^{*}$, $\Delta a^{*}$ and $\Delta b^{*}$ are the differences in $L^{*}, a^{*}$ and $b^{*}$ values before and after immersion at each time interval ${ }^{21}$. For this study, only the $\Delta \mathrm{E}^{*}$ result was used for analysis.

\section{Statistical analysis}

Since the same specimens were evaluated before immersion and after several immersion periods, statistical analysis of data was performed using two-way repeated measures analysis of variance (ANOVA). When significant differences were found, Tukey's post hoc test at $95 \%$ probability level was applied.

\section{RESULTS}

Mean and standard deviation of $\Delta \mathrm{E}^{*}$ for the two brands of denture tooth acrylic resins after 7, 21, $30,45,60$, and 90 immersion cycles for each tested solution are presented in Table 1.

According to the results, the values of $\Delta \mathrm{E}^{*}$ ranged from 0.192 to 0.906 for denture tooth acrylic resin $A$ and from 0.324 to 0.978 for denture tooth acrylic resin T during the 90 cycles of immersion in all solutions.

Generally, through an intra-cycle analysis, the results indicated that all solutions tested during the 90 cycles assessed, except in the $30^{\text {th }}$ and $90^{\text {th }}$ cycles, provided similar changes in color stability $\left(\Delta \mathrm{E}^{*}\right)$ in denture tooth acrylic resin A. Basically, a similar fact was observed for denture tooth acrylic resin $\mathrm{T}$. In this resin, the change in color stability $\left(\Delta \mathrm{E}^{*}\right)$ caused by all solutions tested, except for solution $\mathrm{H} 1 \%$, was similar during the 90 cycles evaluated. In addition, most of the biggest changes in color stability $\left(\Delta \mathrm{E}^{*}\right)$ in both denture tooth acrylic resins studied was caused by solution $\mathrm{W}$.

Through an inter-cycle analysis, as a general rule, the results indicated that all solutions used showed a similar trend in the fluctuation of $\Delta \mathrm{E}^{*}$ in both resins evaluated, in which the variation in $\Delta \mathrm{E}^{*}$ seemed to increase up to the $45^{\text {th }}$ cycle, and from that point a decrease in this fluctuation was observed.

Furthermore, none of the denture tooth acrylic resins tested showed $\Delta \mathrm{E}^{*}$ values higher than 1.0 during the 90 immersion cycles, irrespective of the tested solution.

\section{DISCUSSION}

The use of chemical solutions for denture cleaning has been highlighted due their effectiveness in reducing microorganisms ${ }^{14}$. However, color changes in acrylic resins have been reported as one of the main deleterious effects caused by these substances ${ }^{12,13}$.

Since there is no study available about the effect of chemical solutions on the color stability of denture tooth acrylic resins and this effect is of great esthetic importance to removable denture users, this pioneering research was conducted to evaluate the effect caused by the most widely used substances for removable denture disinfection ${ }^{1,2,3}$. Furthermore, the authors were the first to evaluate 
these alterations over a long period. Some might consider a period of 90 immersion cycles too long for an experimental period. However, an in vitro study over a short period of evaluation could not reliably reproduce the effect of the solutions on the color stability of the denture tooth resins tested. These facts make it difficult to interpret the results of the present investigation because they do not allow a direct comparison with data of other studies.

In this study, color changes in denture tooth acrylic resins were measured by measuring instruments (e.g.: spectrophotometer) ${ }^{10,17}$ instead of visual evaluation. This instrument eliminated the subjective interpretation of visual color alteration. The CIE L*a*b* system for measuring chromacity was chosen to record color changes, as it is well suited for determining small color differences ${ }^{8}$. The $\Delta \mathrm{E}^{*}$ represents relative color changes in the materials an observer might report after treatment or between time periods, hence, $\Delta \mathrm{E}^{*}$ is more meaningful than individual $L^{*}, a^{*}, b^{*}$ values $^{21}$. Therefore, only the $\Delta \mathrm{E}^{*}$ results were selected for analysis.

In general, except for solution $\mathrm{H} 1 \%$ in resin $\mathrm{T}$, all solutions caused similar color changes in both resins studied within each immersion cycle. This was expected, since both resins have the same chemical composition. Moreover, in most cycles assessed, solution $\mathrm{W}$ was responsible for the greatest color changes in both resins. These results could be due to the composition of the materials and the way they are affected by environmental conditions. It is well known from literature that polymer materials undergo water sorption ${ }^{6,23}$. The water may eventually cause irreversible damage to all forms of acrylic by the formation of microcracks as a result of repeated sorption/desorption cycles, which is followed by hydrolytic degradation of the polymer with scission of the ester linkages and gradual deterioration of the infrastructure of the polymer over time ${ }^{23}$. This phenomenon may contribute to form acrylic zones with different optical properties ${ }^{5}$, which can be visibly detected or esthetically unacceptable. Possibly also for this reason, almost all disinfectants constituted by a lower volume of water caused smaller color changes than solution W.

Although sodium hypochlorite presents a whitening effect through oxidation reaction on the surface of denture acrylic resins, this phenomenon was not observed on the materials tested in our study. The acrylic resin teeth evaluated (Artiplus and Trilux) have basically the same chemical composition: high molecular weight polymethyl methacrylate, cross-linked resin and IPN (Interpenetrating Polymer Network). The result is the formation of a polymer with high chemical and physical resistance ${ }^{16}$. Consequently, these superior characteristics also make these materials less prone to the oxidative effects of this disinfectant solution.

Table 1 reveals that for both denture tooth acrylic resins, the major color changes observed in the $\Delta \mathrm{E}^{*}$ occurred up to the $45^{\text {th }}$ cycle. In contrast, from this point, there was a tendency for the $\Delta \mathrm{E}^{*}$ values to decrease until the $90^{\text {th }}$ cycle. This could be explained by the water-sorption saturation in polymeric materials. Yiu, et al. ${ }^{23}$ (2004) found that once the polar sites in the polymer network become saturated with water, equilibrium is reached between bound and free sites and the intermittent water absorption is stabilized. In the present study, it could have occurred as from the $45^{\text {th }}$ cycle, which led to a reduction in the variation of color stability of materials evaluated.

In the present study, although statically significant differences in $\Delta \mathrm{E}^{*}$ values during the 90 immersion cycles were found in both denture tooth acrylic resins, there were no $\Delta \mathrm{E}^{*}$ values higher than 1.0. The trained human eye can detect color changes $\left(\Delta \mathrm{E}^{*}\right)$ greater than 1.0 , but an untrained eye usually cannot distinguish $\Delta \mathrm{E}^{*}$ values below 2.0 in the CIE L*a*b* color system ${ }^{9,10}$. Therefore, the $\Delta \mathrm{E}^{*}$ values found in the present study are clinically important, because they cannot be perceived by the naked eye.

Due to lack of information, further studies are mandatory for better understanding the process of color alteration of denture tooth acrylic resins, evaluating different disinfection procedures, e.g. microwave disinfection, which is highly efficient, and other denture tooth acrylic resin brands.

\section{CONCLUSION}

Within the limitations of this study, it can be concluded that repeated immersion cycles in the solutions altered the color of denture tooth acrylic resins, but this change was not clinically visible.

\section{ACKNOWLEDGMENTS}

This research was supported by the Brazilian foundations CNPq (307510/2010-7) and FAPESP (2006/03383-4). The authors would like to thank the manufacturers (Dentsply International and Dental VIPI Ltda.) for the donation of the materials used in this study and Margery Galbraith for editing the English of the manuscript. 


\section{REFERENCES}

1- Bell JA, Brockmann SL, Feil P, Sackuvich DA. The effectiveness of two disinfectants on denture base acrylic resin with an organic load. J Prosthet Dent. 1989;61(5):580-3.

2- Budtz-Jørgensen E. Materials and methods for cleaning dentures. J Prosthet Dent. 1979;42(6):619-23.

3- Buergers R, Rosentritt M, Schneider-Brachert W, Behr M, Handel G, Hahnel S. Efficacy of denture disinfection methods in controlling Candida albicans colonization in vitro. Acta Odontol Scand. 2008;66(3):174-80.

4- Davenport JC. The oral distribution of Candida in denture stomatitis. Br Dent J. 1970;129(4):151-6

5- Devlin H, Kaushik P. The effect of water absorption on acrylic surface properties. J Prosthodont. 2005;14(4):233-8.

6- Ertaş E, Güler AU, Yücel AC, Köprülü H, Güler E. Color stability of resin composites after immersion in different drinks. Dent Mater J. 2006;25(2):371-6.

7- Gornitsky M, Paradis II, Landaverde G, Malo AM, Velly AM. A clinical and microbiological evaluation of denture cleansers for geriatric patients in long-term care institutions. J Can Dent Assoc. 2002;68(1):39-45.

8- Khokhar ZA, Razzoog ME, Yaman P. Color stability of restorative resins. Quintessence Int. 1991;22(9):733-7.

9- Kiat-Amnuay S, Johnston DA, Powers JM, Jacob RF. Color stability of dry earth pigmented maxillofacial silicone A-2186 subjected to microwave energy exposure. J Prosthodont. 2005;14(2):91-6.

10- Koksal T, Dikbas I. Color stability of different denture teeth materials against various staining agents. Dent Mater J. 2008;27(1):139-44.

11- Ma T, Johnson GH, Gordon GE. Effects of chemical disinfectants on the surface characteristics and color of denture resins. J Prosthet Dent. 1997;77(2):197-204.

12- May KB, Razzoog ME, Koran A $3^{\text {rd }}$, Robinson E. Denture base resins: comparison study of color stability. J Prosthet Dent. $1992 ; 68(1): 78-82$.
13- McNeme SJ, Von Gonten AS, Woolsey GD. Effects of laboratory disinfecting agents on color stability of denture acrylic resins. J Prosthet Dent. 1991;66(1):132-6.

14- Pavarina AC, Pizzolitto AC, Machado AL, Vergani CE, Giampaolo ET. An infection control protocol: effectiveness of immersion solutions to reduce the microbial growth on dental prostheses. J Oral Rehabil. 2003;30(5):532-6.

15- Pavarina AC, Vergani CE, Machado AL, Giampaolo ET, Teraoka MT. The effect of disinfectant solutions on the hardness of acrylic resin denture teeth. J Oral Rehabil. 2003;30(7):749-52.

16- Reis KR, Bonfante G, Pegoraro LF, Conti PC, Oliveira PC, Kaizer OB. In vitro wear resistance of three types of polymethyl methacrylate denture teeth. J Appl Oral Sci. 2008;16(3):176-80. 17- Samra AP, Pereira SK, Delgado LC, Borges CP. Color stability evaluation of aesthetic restorative materials. Braz Oral Res. 2008;22(3):205-10

18- Verran J, Maryan CJ. Retention of Candida albicans on acrylic resin and silicone of different surface topography. J Prosthet Dent. 1997;77(5):535-9.

19- Williams HN, Falkler WA Jr., Hasler JF, Libonati JP. The recovery and significance of nonoral opportunistic pathogenic bacteria in dental laboratory pumice. J Prosthet Dent. 1985;54(5):725-30. 20- Williams HN, Falkler WA Jr., Smith AG, Hasler JF. The isolation of fungi from laboratory dental pumice. J Prosthet Dent. $1986 ; 56(6): 737-40$.

21- Yannikakis SA, Zissis AJ, Polyzois GL, Caroni C. Color stability of provisional resin restorative materials. J Prosthet Dent. 1998;80(5):533-9.

22- Yilmaz H, Aydin C, Bal BT, Ozçelik B. Effects of disinfectants on resilient denture-lining materials contaminated with Staphylococcus aureus, Streptococcus sobrinus, and Candida albicans. Quintessence Int. 2005;36(5):373-81.

23- Yiu CK, King NM, Pashley DH, Suh BI, Carvalho RM, Carrilho $M R$, et al. Effect of resin hydrophilicity and water storage on resin strength. Biomaterials. 2004;25(26):5789-96. 